\title{
Editorial
}

\section{A metamorfose da crise}

The metamorphosis of the crisis

La metamorfosis de la crisis

\author{
Maria do Céu Patrão Neves ${ }^{1}$ \\ André Dias Pereira ${ }^{2}$
}

\section{Resumo}

A consciencialização de vivermos hoje sob o signo de uma tripla crise - sanitária, económica e social - provocada pela pandemia, convida a recuperar o sentido originário arquétipo grego krisis que, na disrupção que anuncia, exprime o corte repentino com o conhecido e familiar, mas também a oportunidade de mudança para melhor. É a metamorfose da crise que inspira um conjunto de textos dedicados à história das pandemias e às consequências éticas, jurídicas e sociais que a pandemia da Sars-Cov-2 trouxe a todo o planeta, principalmente no plano das decisões éticas, das políticas públicas, sob a perspetiva dos direitos humanos. Este editorial problematiza as questões desenvolvidas neste volume, a partir de reflexões de vários continentes e de diversos horizontes discursivos: História, Direito, Filosofia, Medicina, Ciências Sociais e Políticas sanitárias, numa obra que visa a concretização de uma reflexão bioética como ciência inter- e transdisciplinar.

\section{Palavras-chave}

Saúde pública. Pandemias. Direito Sanitário. Bioética.

\begin{abstract}
The awareness that we are currently living a triple crisis - health, economic and social caused by the pandemic, invites us to revisit the original meaning of the Greek archetype krisis which, in the disruption it announces, expresses both a sudden discontinuity with what is known and familiar, and also an opportunity for change, to build a better future. The metamorphosis of the crisis stimulates a set of texts committed to the history of pandemics and the ethical, legal and social consequences that the Sars-Cov-2 pandemic brought to the entire planet, especially in terms of ethical decisions, public policies, from a human rights perspective. This editorial discusses the problems developed in this volume, based on reflections from various Continents and from different discursive horizons: History, Law, Philosophy, Medicine, Social Sciences and Health Policies, in a work that aims to implement a bioethical reflection as an inter- and transdisciplinary.
\end{abstract}

\section{Keywords}

Public Health. Pandemics. Health Law. Bioethics.

\footnotetext{
${ }^{1}$ Professora Catedrática de Ética, Departamento de História, Filosofia e Artes, Faculdade de Ciências Socias e Humanas, Universidade dos Açores, Ponta Delgada, Açores, Portugal. https://orcid.org/0000-0001-7246-6182. E-mail: m.patrao.neves@gmail.com

2 Doutor em Direito Civil; diretor, Centro de Direito Biomédico, Faculdade de Direito, Universidade de Coimbra, Coimbra, Portugal. https://orcid.org/0000-0003-4793-3855. E-mail: andreper@fd.uc.pt
} 


\section{Resumen}

La conciencia de que vivimos hoy bajo el signo de una triple crisis - sanitaria, económica y social - provocada por la pandemia, nos invita a recuperar el significado original del arquetipo griego krisis que, en la disrupción que anuncia, expresa la ruptura repentina con lo que es conocido y familiar, pero también la oportunidad de cambiar para mejor. Es la metamorfosis de la crisis la que inspira un conjunto de textos dedicados a la historia de las pandemias y las consecuencias éticas, legales y sociales que la pandemia Sars-Cov-2 trajo a todo el planeta, especialmente en materia de decisiones éticas, políticas públicas, desde una perspectiva de derechos humanos. En este editorial se analizan los temas desarrollados en este volumen, a partir de reflexiones de varios continentes y de diferentes horizontes discursivos: Historia, Derecho, Filosofía, Medicina, Ciencias Sociales y Políticas de Salud, en un trabajo que pretende implementar una reflexión bioética como inter- y transdisciplinar.

\section{Palavras clave}

Salud Pública. Pandemias. Derecho Sanitario. Bioética.

Vivemos, desde há demasiados meses, há mais de um ano, um tempo ferido de crise. Uma crise sanitária, provocada por uma nova estirpe do coronavírus (SARS-CoV-2) e que se tem vindo a desdobrar em diversas variantes, a qual conduziu a uma crise económica, ditada pelo isolamento social e a vários ritmos de confinamentos das actividades económicas como única estratégia eficaz de controle do surto infecioso, a qual, por sua vez, depressa degenerou numa crise social, pela paralisação ou atrofiamento do trabalho, repercutindo-se nas falências, desemprego e pobreza, numa suspensão dos meios comuns de subsistência.

Vivemos, pois, uma tripla crise que se alastrou e invadiu todas as actividades humanas, tendo destruído as rotinas, rompido com a noção de normalidade e assim contaminando o nosso quotidiano que se converteu num desconhecido inseguro e ameaçador. Foi uma mudança brusca, porque repentina e agressiva, ao mesmo tempo que severa. A crise é sempre disruptiva. É para esta realidade, agora individualmente experienciada, que remete o arquétipo grego krisis, o qual exprime também o imperativo de uma excruciante tomada de decisão. Quando os caminhos conhecidos se apagam, por onde seguir? A crise é também o momento da decisão, qual rito de passagem para uma nova dimensão da realidade ou metamorfose para uma nova expressão do ser. Projectamo-nos, sem alternativa, para o inédito. Mas, afinal, também não andávamos há muito à procura do novo, de novas formas de realidade, de novas formas de ser? O 'novo', porém, não é necessariamente melhor. É diferente. E pode ser pior. Mas é esta pluralidade de vias que nos permite abrir das dificuldades que a crise representa para o sentido de oportunidade que Ihe está igualmente associado.

Todas as crises são metamorfósicas, todas constituem oportunidades de mudança, oportunidades para nos libertarmos de tantos estabelecidos que nos amarram e cujo lastro 
nos mantém reféns, oportunidades para inventarmos o futuro sem o remorso de quebramos com alguns traços do passado.

Aspira-se agora, nas dores da crise, à metamorfose de um novo nascimento, à sabedoria de decidir pelas melhores oportunidades, enveredando por um espaço largo, em que todos caibam, um caminho sólido, construído pelo conhecimento do passado e as experiências do presente, em direcção a um horizonte rasgado, acolhedor do arrojo e da ambição. Este 'melhor' só os valores decidem, porque são a única medida para o mau e para o bom, para avaliar ou apreciar se é pior ou melhor. Na conversão das dificuldades em oportunidades, a metamorfose da crise será decidida pelos valores por que optarmos.

Podemo-lo constatar em diversas experiências da pandemia nos domínios da vida comunitária em convulsão - o da saúde, da economia e o social -, nas dificuldades que estes impuseram, nas oportunidades que abrem e nos valores que convocam.

Consideremos primeiramente alguns exemplos comuns no domínio da saúde, no seu âmbito mais alargado da biomedicina, em que também a crise se originou. Na prestação dos cuidados de saúde, a pressão foi desde sempre dupla: cuidar dos doentes COVID-19 e também de todos os outros que foram vendo adiado o seu tratamento, primeiro com receio de se deslocarem aos hospitais e aí serem infectados, depois porque os hospitais não tinham capacidade para deles cuidar. Uma das questões mais dramáticas tem sido a da selecção de doentes nos cuidados intensivos, ou até para acesso a hospitais, a camas, a oxigénio, com uma forte tendência para utilizar a idade avançada como critério de exclusão, o que constitui uma violação flagrante do princípio da dignidade humana. Afinal, condenamos na nossa sociedade racismo, xenofobia, sexismo... porque rejeitamos que características como a etnia, a nacionalidade ou o género definam a pessoa na sua essência e sejam utilizadas como critérios da sua diferente classificação. Mas desvalorizamos os mais velhos, atribuindo valor à pessoa consoante a idade, como se a dignidade humana se gastasse com os anos.

$E$, não obstante, entre as dificuldades na assistência clínica, há indícios de metamorfose. Por exemplo, tem-se verificado um excepcional reforço de medidas de higiene, o que deverá prevalecer para além da pandemia. A implementação rigorosa das boas práticas de higienização, desinfeção, esterilização dos profissionais de saúde e dos serviços, deverá diminuir o risco de infecções hospitalares. Estas vinham aumentando em número e severidade, o que se torna ainda mais grave quando a eficácia dos antibióticos está a diminuir. Também se tem registado um acelerado recurso à telesaúde, à telemedicina a qual, adoptada como complementar e não alternativa, deverá facilitar e ampliar a acessibilidade dos cidadãos aos cuidados, bem como uma economia de recursos e de 
tempo, isto é, uma redução de custos por parte das administrações, contribuindo para a optimização dos recursos de saúde.

O Serviço Nacional de Saúde terá também ganho maior flexibilidade e deverá continuar a merecer reforço de recursos humanos e de equipamentos, enquanto se acentua a relação entre a actividade assistencial e a de investigação numa qualificação clínica. Somam-se assim sinais de uma mais próxima e eficaz prestação dos cuidados de saúde.

No plano da investigação biomédica, a mobilização da comunidade científica para a criação de vacinas seguras e eficazes contra a COVID-19 conduziu de imediato ao encerramento, suspensão e adiamento de muitos ensaios clínicos sobre outras patologias, com grande prejuízo para o progresso biomédico em geral. Um outro tipo de acontecimento, controverso, que tem passado desapercebido, é o da selecção de voluntários para os ensaios clínicos, pagos para se deixarem infectar pelo coronavírus. Estes voluntários remunerados são pessoas carenciadas, e a exploração da sua fragilidade constitui mais uma modalidade de violação da dignidade humana. Também mais tarde, uma suposta gratuitidade de vacinas em troca do acesso a dados de saúde de todos os vacinados, opta pela beneficente vacinação tão rápida e ampla da população quanto possível, mas comercializando o que é de pertença individual e expondo a privacidade de cada um.

Mas também ao nível da investigação cedo começou a existir indícios de metamorfose na excepcional colaboração da comunidade científica mundial reunida no empenho quer da criação de vacinas, quer da descoberta de tratamentos eficazes. Esta comunidade tornouse mais alargada do que nunca e mais cooperante que jamais, o que potencializou os objectivos das várias equipas, em menos tempo e com menos custos. É certo que à medida que o sucesso se foi tornando evidente, a cooperação se foi apagando e de novo substituída pela competição. Prevaleceu a experiência de que a investigação científica estruturada sob o signo da cooperação não se toma como fim e antes se reconhece como meio de realização do bem comum, de promoção do humano, o único fim em si mesmo pela dignidade ou valor intrínseco que lhe assiste.

Consideremos seguidamente alguns exemplos comuns também no domínio da economia acompanhando o impacto que atingiu as várias fileiras produtivas, de jusante para montante, isto é, da comercialização à produção. O confinamento decretado na generalidade dos países encerrou serviços e comércio e também a maior parte da indústria, tendo ainda atingido o sector produtivo, ao mesmo tempo que encerrou todos os consumidores e cada cidadão na sua casa. Surpreendentemente, aquele arreigado sonho de poder ficar em casa, com a família, em vez de ir trabalhar, depressa se esfumou, tendo-se descoberto a importância do trabalho na realização pessoal e na interacção social. Ao mesmo tempo, este 
regresso forçado a nós mesmos e a momentos introspectivos, à família próxima e ao confronto continuado com a personalidade de cada um, revelou a exigência de autenticidade, fidelidade e complacência, virtudes que talvez andassem arredadas das nossas vidas.

Entretanto, o trabalho que prosseguiu, para além dos serviços prioritários - da saúde ao abastecimento alimentar - foi apenas o que se podia e soube adaptar à distância, o trabalho remoto, o que obriga a repensar os critérios de distribuição dos bens públicos no compromisso com a justiça social. Esta flexibilização do trabalho, que há muito se reclamava, tenderá a persistir e mesmo a desenvolver-se, o que funcionará sempre melhor se o próprio trabalho se organizar por tarefas ou objectivos e não pela obrigatoriedade de uma duração previamente estabelecida.

Há, pois, metamorfoses em curso como reação à crise. O impacto do teletrabalho ao nível dos transportes poderá ser de redução na sua utilização futura, com uma consequente diminuição do trânsito, melhoria da qualidade do ar, decréscimo de problemas respiratórios. Outro exemplo será o das competências informáticas, que há muito se afirmavam como uma mais-valia dos jovens, e que se vão tornando básicas para todas as gerações.

A digitalização da economia acelerou em tempo de pandemia não apenas no domínio do trabalho, mas também da organização da produção, com um direcionamento para as necessidades reais e urgentes das pessoas, e da comercialização, com uma crescente variedade de produtos online. Este é um processo que se continuará a intensificar e a que todas as médias e pequenas empresas terão de responder para sobreviver. Simultaneamente, indústria e comércio têm procurado inovar os seus padrões de actividade, para responderem às condições actuais da actividade económica, revelando resiliência, flexibilidade e inovação, competências que lhe serão muito úteis para qualquer futuro que se venha a desenhar.

Nestes processos acelerados de mudança há sempre diferentes andamentos e muitos são os que ficam para trás, por diversas razões - a idade avançada, as capacidades reduzidas, as circunstâncias adversas -, aprofundando-se fossos sociais que temos de contrariar, não só porque todas as pessoas são iguais em dignidade, mas também porque a justiça, ou o tratamento equitativo de todos, é um projecto colectivo que só se concretiza verdadeiramente quando é inclusivo.

O soçobrar da economia tem tido um impacto directo na sociedade, imediatamente no desemprego ou ausência de actividade remunerada - e estas são mais algumas experiências comuns da pandemia agora no âmbito social. Com efeito, qualquer que seja o sistema de protecção social, todos os dias há mais pessoas a cair em situação de pobreza. 
Para além das obrigações do Estado, a resposta da sociedade civil tem sido excepcional sobretudo na distribuição de bens alimentares e de primeira necessidade, inclusivamente na sua entrega domiciliária a idosos. Aliás, a crise desencadeou a organização de bolsas de voluntários para desenvolvimento de diversos serviços, no despertar de sentimentos de partilha para com os mais carenciados. As situações de emergência social, no seu profundo dramatismo, revestem-se também da magia de despertar sentimentos altruístas e acções de solidariedade. A metamorfose social seria manter esta vivência de fraternidade no reconhecimento continuado do outro como um igual a mim que exige a solidariedade entre todos.

Indicámos já que as actividades que desde o desencadear da crise sanitária persistiram foram as que se podiam exercer remotamente e as que satisfazem necessidades reais num quadro de proximidade. Estes aspectos influenciarão os domínios em que mais se investirá, nomeadamente das ciências biomédicas e das tecnologias de informação e da comunicação, o que terá impacto tanto no emprego como na educação, com uma maior exigência educativa para a maior parte dos empregos. No sector da educação, sobretudo nos níveis superiores de ensino, o contacto remoto pode não apenas ser complementar às anteriores modalidades estabelecidas de ensino, mas favorecer novas formas de interrelação, mais receptivas a uma diversidade de colaborações, de ensino-aprendizagem, tendencialmente mais autónomo.

De facto, não estamos apenas num processo avassalador de digitalização da economia, mas de digitalização da sociedade e do humano o que nos conduz, quase irreprimivelmente, a perguntas de carácter existencial. Que impacto terá nas nossas vidas esta proximidade virtual e afastamento físico, que a intervenção crescente nas redes sociais há muito anunciava e agora se intensifica a todos os níveis de actividade? Não sentem um potencial adormecimento da diversidade dos sentidos na sua redução à visão, no afunilamento dos sentidos à interacção com o visualizável? Os riscos de ilusões ópticas multiplicam-se numa afectação que não se confina aos sentidos, mas invade o intelecto, numa maior dificuldade em consciencializar a distinção entre o físico e o virtual, entre o frenesi do mundo e o asséptico écran, um espaço sem horizonte em que até o eu pode adoptar a identidade que quiser na second life, sem o esforço a que a perfectibilização moral do carácter exige. Como será o meu eu na minha sociedade metamorfoseada? São questões que não cabe, no actual contexto, desenvolver, mas que convirá não apagar do contexto mais alargado da metamorfose da crise.

Estas experiências da pandemia - escassas e apenas ilustrativas - expõem dificuldades, mas igualmente oportunidades. Entretanto, percebemos que as metamorfoses 
da crise não são axiologicamente neutras; exprimem valores que traçam o perfil da nossa identidade e projectam o futuro das nossas sociedades: o princípio da dignidade humana, tão colocado em causa no domínio da saúde, exige respeito pelo valor absoluto, incondicional e inalienável de cada pessoa; o princípio da justiça social, tão ameaçado no domínio da economia, exige a consideração igual de todos os cidadãos; o princípio da solidariedade, tão requisitado pela sociedade, exige o descentramento de si na atenção ao outro.

A realidade sucintamente apresentada torna-se ainda mais evidente em experiências transversais, na medida em que não se referem apenas às diferentes actividades das pessoas - na saúde, economia, sociedade -, mas à pessoa mesma, singularmente considerada. E neste plano vivencial, talvez a mais originária experiência desta pandemia seja a da nossa vulnerabilidade. O vírus não escolhe género, etnia, nacionalidade ou religião, nem tão pouco nível de educação ou estrato social e todos podemos ser infectados, não obstante reconhecermos que as vulnerabilidades socioeconómicas agravam a vulnerabilidade sanitária. É evidente que o ser humano é inalienavelmente vulnerável uma vez que é mortal, mas vivemos frequentemente como se nada nos pudesse atingir. A consciência que agora se intensificou da nossa vulnerabilidade devia ensinar-nos a ser humildes e ajudar a reconhecermo-nos como iguais.

Paralelamente abre-nos à experiência de uma indissolúvel interdependência. Uma pandemia, e tantos outros problemas mundiais como são os da fome, da guerra ou ambientais, não podem ser resolvidos, nas suas causas como nos seus efeitos, isoladamente, por países, sem concertações mundiais, sem uma governança global que reúna governos e cidadãos e desenhe orientações maximamente consensuais para o nosso futuro comum. Assim se deve exprimir a nossa interdependência que decorre de habitarmos o mesmo tempo e o mesmo espaço.

A pungência da nossa vulnerabilidade e a autenticidade da nossa interdependência revelam-nos uma identidade originária e uma condição partilhada da humanidade, a que a dignidade pessoal, a justiça social e a solidariedade fraternal respondem.

$\mathrm{Na}$ metamorfose da crise, quais os valores que queremos preservar? Os do individualismo dos mais fortes que enfraquece a maioria ou os da solidariedade global que a todos fortalece?

É neste amplo contexto que nos propomos fazer uma análise da crise sanitária global desencadeada pela pandemia de SARS-CoV-2, destacando algumas das temáticas mais marcantes para a caracterização da situação actual de crise, mas sobretudo para o traçar da sua metamorfose futura. Para além da atenção ao presente queremos um olhar 
prospectivo para o qual a actual pandemia é mais mote do que tema. E projectamo-lo na composição de diferentes quadros, delineando as "questões éticas e perspectivas jurídicas no âmbito da pandemia" pelo esboçar da "história das pandemias e evolução clínica", no presente volume, para construir um quadríptico, no próximo volume, com o esquisso da "investigação clínica e cooperação internacional".

Adoptamos assim, neste volume, primeiramente uma perspectiva histórica que, incidindo nas grandes epidemias na história da humanidade, procura evidenciar que: a realidade pandémica de hoje não é nova; subsistem fortes semelhanças entre a vivência e as medidas de mitigação da pandemia em diferentes contextos históricos; podíamos ainda hoje aprender com as lições do passado, com benefício futuro; existem aspectos específicos do nosso presente que intervieram no conhecimento dos seu surgimento, na velocidade da sua expansão, na pluralidade de meios de controle, como na sua abordagem preventiva e terapêutica - o que vai sendo construído sucessivamente por Adalberto Campos Fernandes em "As grandes pandemias da história da Europa e os seus impactos na nossa civilização"; por Maria Paula Diogo e Ana Simões em "Epidemias e os avisos surdos da história"; e por José Roberto Goldim e Márcia Santana Fernandes em "Os novos contextos da disseminação de doenças".

Segue-se uma perspectiva vincadamente biomédica na abordagem de questões fundamentais no âmbito da prestação de cuidados de saúde, sobretudo num contexto infectocontagioso, como sejam, "O bem da pessoa, o bem comum e a objecção de consciência" de Michel Renaud; "Relação médico-paciente na assistência em contexto pandêmico" de Camila Vasconcelos e Elda Bussinguer; "Critérios de triagem em pandemia" de M. Patrão Neves; "Instrumentos de ação do Poder Público empregados para o enfretamento da COVID-19" de Auxiliadora Minahim e Lucas Santos Costa; "Direito Penal e COVID-19 no espaço lusófono" de Inês Godinho, "Proteção jurídica dos profissionais de saúde envolvidos no atendimento em contexto da pandemia da COVID-19" de André Dias Pereira, Javier Barceló e Nelson Rosenvald; "Promoção da saúde pública e protecção dos direitos fundamentais" de Ana Raquel Moniz; "Proteção de dados e segurança informática no setor da saúde" de Alexandre Dias Pereira; e "Educar para la salud en tiempos de pandemia", de Vicente Bellver Capella. Este itinerário parte, pois, da questão fundamental do bem individual e do bem comum que enquadra todo o debate subsequente, e detém-se em algumas questões particulares que ganharam uma especificidade acrescida durante a pandemia. A reflexão jurídica desenvolve abordagens distintas em contextos diversos, numa crescente amplitude, e a secção encerra com a temática fundamental da promoção da literacia em saúde. 
Algumas comunicações breves complementam as temáticas abordadas, tal como se verifica com "Contágios" de Jaime Nogueira Pinto; "A pandemia da COVID-19 no espaço da Lusofonia" de Orquídea Massarongo; e "El proceso de muerte en la pandemia por coronavirus" de Eduardo Osuna. E o volume encerra como a apresentação comentada de alguns documentos legislativos relevantes para o actual contexto, como sejam, "A gestão da pandemia SARS-CoV-2 em Angola" por Cristovão Simões; "Estratégias de eliminação da pandemia COVID-19 na Ásia-Pacífico" por Rui Cascão; e "New law preventing COVID-19", por Ilise Feitshan e ainda com uma selecção e recensão de textos pertinentes, por Carla Barbosa. Estas últimas secções do presente volume, em particular, beneficiam do trabalho da equipa de investigadores do projecto "Responsabilidade em Saúde Pública no Mundo Lusófono: fazendo justiça durante e para além da emergência da COVID", patrocinado pela Organização Mundial da Saúde (OMS) e realizado sob a égide do Instituto Jurídico da Faculdade de Direito da Universidade de Coimbra, e que, numa abordagem transnacional, recolheu e analisou dados relativos à preparação e resposta dadas à pandemia da COVID19 em Angola, Brasil, Moçambique, Portugal e Região Administrativa Especial de Macau (RAEM).

O presente volume dos Cadernos Ibero-Americanos de Direito Sanitário oferece-se ao leitor ainda em plena crise pandémica, quando as vacinas já circulam, mas a sua distribuição é desigual, mantendo-se os problemas sanitários, persistindo os económicos e aprofundando-se os sociais. A pandemia é, por definição, global e terá tido o condão de obrigar a todos e a cada um de nós a consciencializar a sua vulnerabilidade e a nossa interdependência, isto é, de consciencializar que também só em conjunto poderemos ultrapassar a pandemia. O problema é global, pelo que a superação terá de ser global também, fazendo-nos pelo menos reconhecer que somos todos vizinhos, se não conseguirmos viver como irmãos - parafraseando o Papa Francisco na Fratelli Tutti. E esta deverá ser a metamorfose da crise para a qual o presente volume do CIADS procura contribuir através da sua reflexão temática ampla e da perspectiva diversa acerca da crise sanitária.

\section{Como citar este artigo}

Submetido em: 14/06/2021 Aprovado em: 14/06/2021

Patrão Neves MC, Dias Pereira A. A metamorfose da crise. Cadernos Ibero-Americanos de Direito Sanitário. 2021 abr./jun.;10(2):10-18.

https://doi.org/10.17566/ciads.v10i2.809 